\title{
СИСТЕМЫ ЭНЕРГООБЕСПЕЧЕНИЯ С АЛЬТЕРНАТИВНЫМИ ИСТОЧНИКАМИ ЭНЕРГИИ: БЕЗОПАСНОСТЬ ФУНКЦИОНИРОВАНИЯ АКУСТИЧЕСКИХ ИСТОЧНИКОВ
}

Г.И. Сокол, докт. техн. наук, проф., Л.В. Накашидзе, докт. техн. наук, с.н.с. директор НИИ энергетики, С.Ю. Кириченко, вед. инженер

Днепровский национальный университет имени Олеся Гончара 49050, пр-т Гагарина, 72, г. Днепр, Украина

Одним из последствий позитивного процесса науки и техники являются сопутствующие явления, в том числе и негативные. При разработке установок, преобразующих энергию альтернативных источников, еще на этапе проектирования необходимо предусматривать снижение уровней интенсивности шумов. Эти мероприятия необходимь для обеспечения защчиты окружающей среды от иумового загрязнения. Для разработки мероприятий, направленных на снижение звукового давления (УЗД) в шумах до уровня, предусмотренного нормативными документами [1], необходимо провести анализ иумов от оборудования, которое обеспечивает преобразование энергии альтернативных источников.

Для безопасного функиионирования таких установок необходимо:

- определиться с источниками акустического излучения;

- разработать теоретические основы прочесса генерирования иума;

- осуществить разработку расчетных моделей характеристик акустических полей.

В таком ракурсе, не вызывает сомнений актуальность проблемы снижения шумов от конструктивных элементов систем энергообеспечения, в которых преобразуется энергия солнечного излучения, энергия ветрового потенциала, тепло окружающей среды и т.п. При этом необходимо исключить вредное влияние шумов на людей на прилегающих территориях и в жильх постройках, а также живых обитателей природы.

Результатом проведенных исследований является формирование мероприятий по снижению уровня иумов инфразвукового диапазона. При проектировании инновационных систем энергообеспечения необходимо использовать компоненть, определяюшие не только уровень иума, но и КПД используемьх агрегатов. Так, например, для тепловьх насосов выгодно использовать малошумные элементы, размещать компрессор снаружи здания или размещзать его в звуконепроницаемую камеру. Размещение ВЭУ на удаленном расстоянии от жилой застройки.

Непрерывный иум тепловых насосов можно снижать применением ротационного компрессора вместо пориневого, отказом от применения клапанов, как в некоторых ротационных компрессорах. Пориневые компрессоры следует хорошо балансировать для снижения вибраций и монтировать на виброгасящем основании. Выбор хладагента может влиять на уровень иума - предпочтителен более плотный пар, но если с ним связано повымение давления, то может быть и обратный эффект. В ветроагрегатах предлагается снижение скорости ротора в ночное время.

Предложена методика, которая позволяет эффективно провести расчет УЗД первых инфразвуковых гармоник (2,4 Ги; 4,8 Ги; 9,16 Гц; 18, 32 Ги) и определить их характеристики направленности. Библ. 13, рис. 1.

Ключевые слова: иумы, снижение, тепловые насосы, ветроагрегаты, методика расчета, инфразвуковые гармоники.

\section{SYSTEM OF POWER SUPPLY WITH ALTERNATIVE ENERGY SOURCES: SECURITY OF ACOUSTIC SOURCES' FUNCTIONING} G. Sokol, doctor of technical science, professor, L. Nakashidze, doctor of technical science, senior researcher, director of Energy
Research Institute, S. Kirichenko, leading engineer

Oles Honchar Dnipro National University

49050, Gagarina ave 72, Dnipro, Ukraine

One of the effects of the positive process of science and technology are related phenomena, including negative. It is necessary to provide lower levels of noise intensity at the design stage in the development of alternative sources of energy converting systems. These measures are necessary to protect the environment from noise pollution. In order to develop measures aimed at reducing the sound pressure $(S P L)$ in the noise to the level required by normative documents [1] it is necessary to analyze the noise from the equipment, which provides conversion of alternative energy sources.

For the safe functioning of such facilities, it is necessary:

- to determine the sources of acoustic emission;

- to develop the theoretical basis of the noise generating process;

- to carry out the development of calculation models of ultrasound fields.

In this perspective, there is no doubt about the relevance of the problem of reducing noises from the structural elements of power supply systems, where the energy of solar radiation, the energy of the wind potential, warm environment etc. are converted. The harmful effects of noises on people in the surrounding areas or in residential buildings, as well as the nature inhabitants, should be eliminated. 
The result of conducted researches is the formation measures to reduce the noise level of infrasound range. In the design of innovative power supply systems it is necessary to use components that determine not only level of noise, but also the efficiency of the used aggregates. For example, for heat pumps it is beneficial to use low noise elements, compressor must be placed outside the building or in a soundproof chamber. Placing of wind turbines should be at a remote distance from the residential area. Continuous noise of the heat pumps can be reduced by using a rotary compressor instead of a piston, rejection of applying the valve, as in some rotary compressors. Piston compressors should be well balanced to reduce vibration and be mounted on vibration damping base. The choice of refrigerant may affect the level of noise (denser vapor is preferred), but if it involves increase of pressure, there may be the opposite effect. It is proposed to decrease the rotor speed of the wind turbines at night.

The method, which allows effective calculation of SPL of the first infrasound harmonics $(2.4 \mathrm{~Hz}, 4.8 \mathrm{~Hz}, 9.16 \mathrm{~Hz}, 18,32 \mathrm{~Hz})$ and determination of their directional characteristics is proposed. Ref. 13, fig. 1.

Keywords: noise, reduce, heat pumps, wind turbines, method of calculation, infrasound harmonics.
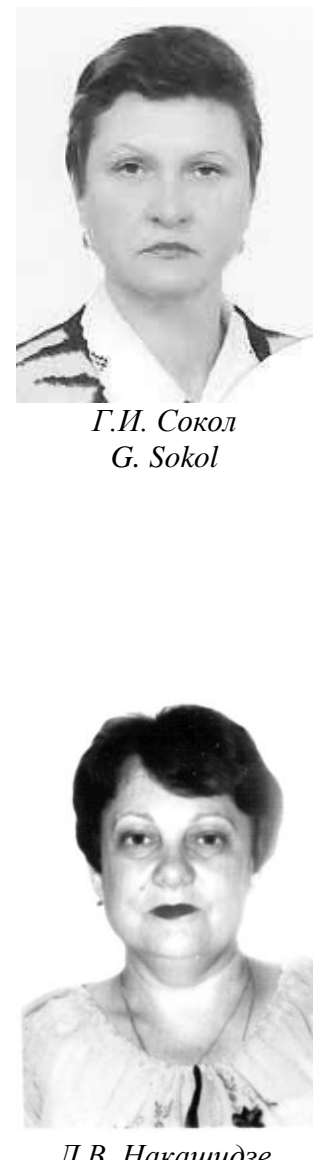
L. Nakashidze

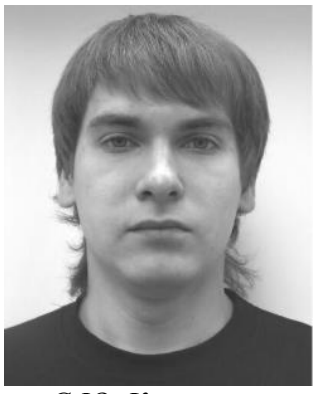

С.Ю. Кириченко S. Kirichenko
Сведения об авторе: доктор техн. наук, профессор, профессор кафедры механотроники физико-технического факультета Днепропетровского национального университета имени Олеся Гончара.

Образование: Днепропетровского государственный университет, физикотехнический факультет, специальность инженер-механик (1971).

Научная сфера: возобновляемые и нетрадиционные источники энергии, инфразвуковые акустические шумы.

Публикации: 360 научных работ, в том числе 22 патента.

ORCID: 0000-0002-6183-9155

Контакти:

тел./факс: (056) 373-12-60

e-mail: gsokol@ukr.net

Сведения об авторе: канд. техн. наук, старш. научн. сотр., директор НИИ энергетики Днепропетровского национального университета имени Олеся Гончара.

Образование: Днепропетровский химикотехнологический институт, факультет технология неорганических соединений, специальность технология неорганических соединений (1985).

Научная сфера: возобновляемые и нетрадиционные источники энергии. Публикации: 95 научных работ, в том числе 3 патента.

ORCID: 0000-0003-3990-6718

Контакти:

тел.: (056) 3731278

e-mail: foton_dnu@ukr.net

Сведения об авторе: ведущий инженер НИИ энергетики Днепропетровского национального университета имени Олеся Гончара.

Образование: Днепропетровский национальный университет имени Олеся Гончара, физико-технический факультет, специальность инженер-энергетик (2015 г.).

Научная сфера: возобновляемые и нетрадиционные источники энергии, инфразвуковые акустические шумы.

Публикации: 6 научных работ.

ORCID: 0000-0002-8860-1593

Контакти:

тел.: 0633668292

e-mail: kirichenkosergey1992@gmail.com
Author information: Doctor of technical sciences, Professor, Department of mechatronics Faculty of Physical

Engineering Oles Honchar Dnipropetrovsk National University.

Education: Dnepropetrovsk State

University, Faculty of Physics and

Technology, majoring in mechanical engineering (1971).

Research area: renewable and nonconventional energy sources, infrasound acoustic noise.

Publications: 360 scientific publications, including 22 patents.

ORCID: 0000-0002-6183-91559

Contacts:

tel./fax: (056) 373-12-60

e-mail: gsokol@ukr.net

Author information: Doctor of technical sciences, director of the Energy Research Institute Oles Honchar Dnipropetrovsk National University.

Education: Dnepropetrovsk Institute of

Chemical Technology, Faculty of

Technology of inorganic compounds, specialty technology of inorganic compounds (1985).

Research area: the renewable and

alternative energy sources.

Publications: 95 scientific papers, including

3 patents.

ORCID: 0000-0003-3990-6718

Contacts:

tel.: (056) 3731278

e-mail: foton_dnu@ukr.net

Author information: leading engineer of the Energy Research Institute Oles Honchar Dnipropetrovsk National University.

Education: Oles Honchar Dnipropetrovsk National University, специальность инженер-энергетик (2015).

Research area: renewable and nonconventional energy sources, infrasound acoustic noise.

Publications: 6 scientific papers.

ORCID: 0000-0002-8860-1593

Contacts:

tel.: 0633668292

e-mail: kirichenkosergey1992@gmail.com 
Введение. Необходимость использования возобновляемых источников энергии (ВИЭ) в экономике развитых стран обусловлена не только ограниченными запасами полезных ископаемых, но и требованиями уменьшения выбросов в атмосферу парниковых газов. Потребление ВИЭ не сопровождается эмиссией $\mathrm{CO}_{2}$, что позволит глобально понизить масштабы выбросов этого газа. Таким образом, использование ВИЭ в качестве первичных энергоисточников не приносит дополнительного энерговнесения в тепловой баланс планеты. Однако при разработке ВИЭ должна решаться проблема обеспечения низких уровней интенсивности шумов и защиты окружающей среды от шумового загрязнения.

Для разработки мероприятий, направленных на снижение уровня звукового давления (УЗД) в шумах до требуемого по санитарным нормам Украины [1], необходимо провести анализ шумов от ВИЭ. В первую очередь надо определиться с источниками акустического излучения, разработать теоретические основы процесса генерирования, осуществить разработку расчетных моделей характеристик акустических полей. В таком ракурсе актуальность проблемы снижения шумов от ВИЭ не вызывает сомнений, так как необходимо исключить вредное влияние шумов на людей на прилегающих территориях и в жилых постройках, а также живых обитателей природы.

Постановка задачи. Особенно важно решить проблему снижения УЗД шумов на инфразвуковых частотах [2]. В инновационных системах энергообеспечения, в которых используется энергия альтернативных источников, в качестве элементов преобразования могут быть тепловые насосы, ветроагрегаты и др. Известно, что их функционирование связано с появлением шумов. Мероприятия, необходимые для решения задачи о снижении шумов, например, тепловых насосов, роторов ветроагрегатов, определятся нормативными документами по допустимым уровням шумов [3]. В стандартах Европейского союза принят допустимый уровень шумов 45 дБ на расстоянии 100-400 м от источника шума.

В [4] показано, что уровень инфразвука от работающего ветроагрегата мощностью 250 кВт не превышает уровень общего шума для производственных помещений и составляет менее 80 дБ на расстоянии 400 м от ВЭУ.

В тепловых насосах [5], используемых в инновационных системах энергообеспечения, шумы появляются благодаря наличию компрессоров различных типов. Предусмотренные в конструкции тепловых насосов звукоизолирующие кожухи, обеспечивают уменьшение уровня шума до 30 дБ.
Источниками генерирования шумов могут быть используемые в системах энергогенерирования известные ветровые агрегаты горизонтально-осевые (ГО), пропеллерного типа, вертикально-осевые (ВО), роторы Дарье и Савониуса $[6,7,8]$.

В технических характеристиках двухлопастных роторов ВО ВЭУ-0020 и ВЭУ-0030, разработанные Международной Научнопромышленной корпорацией «ВЕСТА», указано, что круговая частота вращения ротора 28-90 об/мин. Это приводит к генерированию инфразвука с частотой 2-7 Гц.

В [9] представлены проектные данные ветродвигателя «Эсперо» (ГО) с тремя лопастями. При числе оборотов ветроколеса 67

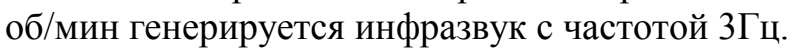

В [6] представлены ветроагрегаты ВЭУ250С и ВЭУ-500 разработки ГКБ «Южное» с трехлопастным ветроколесом с частотой оборотов составляет 47,6 об/мин. Они являются излучателями инфразвука с частотой 2,4 Гц.

В [10] представлены данные измерений на расстоянии 36 м от ВЭУ на частоте 2,5 Гц с УЗД 70 дБ, проведенные по программе NASA. Представлена характеристика направленности инфразвука на частоте 8 Гц для ВЭУ мощностью 100 кВт.

В тепловых насосах, как правило, используется компрессор с частотой вращения около 3000 об/мин, что приводит к генерации инфразвука. Поэтому при эксплуатации моделей тепловых насосов с тепловой мощностью более 15-18 кВт необходимо предусматривать наличие отдельных помещений, а для моделей 40-100 кВт возможно применение дополнительных мер по шумоизоляции помещения котельной.

Шум, издаваемый насосом, неразрывно связан с частотой вращения рабочего колеса, поэтому повлиять на него можно лишь снижая частоту вращения. Но с понижением частоты вращения снижается и производительность насоса, поэтому установка регулятора частоты может дать существенный эффект в том случае, если насос подобран с большим запасом, а также в системах с пиковым повышением водопотребления [11].

Целью данной работы является разработка методик, позволяющих предусмотреть на этапе проектирования минимизацию негативных шумовых воздействий конструктивных элементов систем энергообеспечения при использовании альтернативных источников.

Актуальность решения проблемы определена тем, что шумовое загрязнение как форма физического антропогенного загрязнения окружающей среды появляется в результате превышения 
природного фонового уровня.

Широкомасштабное внедрение систем энергообеспечения с использованием энергии альтернативных источников не должно трансформировать характеристики шумов населенных пунктов (т.е. в местах жизнедеятельности человека) и не менять акустические характеристики на рабочих местах.

Особенности появления акустического загрязнения окружающей среды при функционировании систем преобразования энергии альтернативных источников. В системах энергообеспечения основными конструктивными элементами являются сложные агрегаты, такие как тепловые насосы, ветроагрегаты и т.д. Эти агрегаты при функционировании являются источниками шума. При этом первичным источником колебаний могут быть вибрация частей агрегатов. По мере распространения вибрации по конструкции возбуждаются колебания в окружающей среде (воздухе).

При разработке методов снижения шума очень важным является вопрос о первичном источнике колебаний. Одним из примеров таких источников может быть вращающие лопасти ротора ветроколеса $[4,7]$.

$\begin{array}{ccr}\text { Методика } & \text { расчета инфразвуковых } \\ \text { характеристик } & \text { акустического поля }\end{array}$
ветроколеса. Охарактеризовать звуковое поле генератора ветроколеса возможно, используя теорию Л.Я. Гутина, которая описывает звуковое поле воздушного винта [12].

На каждый элемент колеса действуют две силы: аэродинамическая сила и сопротивление вращательному движению.

Из законов механики следует, что этот элемент, в свою очередь, воздействует на среду с равными по величине и противоположно направленными силами. Точки приложения этих сил будем считать сосредоточенными в одной плоскости, так как осевое протяжение лопасти ничтожно мало в сравнении с длинами волн первых гармоник. Л.Я. Гутин назвал эту плоскость плоскостью вращения (например, протяженность лопасти ВЭУ - 250С составляет 12 м, а длина волны первой гармоники на частоте 2,4 Гц равна 141,6 м).

Рассмотрим элемент лопасти, расстояние до которого от оси ветроколеса равно $R$; пусть $d R-$ его радиальная длина и $a$ - ширина, измеренная в проекции на плоскость вращения.

Силы, с которыми элемент воздействует на среду, обозначим: $A(R) d R$ (параллельна оси и направлена обратно направлению оси ветроагрегата, ось колеса ветроагрегата считаем совпадающей с осью ротора, ее положительное направление - от головки ветроагрегата в пространство) и $B(R) d R$ направлена обратно вращательному движению ротора ветроагрегата:

$$
\begin{aligned}
& n \int_{0}^{R_{0}} A(R) d R=n \int_{0}^{R_{0}} d P=P ; \\
& n \int_{0}^{R_{0}} B(R) d R=n \int_{0}^{R_{0}} d M=M,
\end{aligned}
$$

где $n$ - число лопастей; $R_{0}$ - длина лопасти; $P$ аэродинамическая сила, приводящая лопасть в движение; $M$ - момент во вращательном движении лопасти.

Если прохождение лопасти началось в момент времени $\mathrm{t}=0$, то оно будет закончено во время $\tau$. Периодически повторяющиеся с периодом Т силы разложим в ряд Фурье

$$
\begin{aligned}
& F_{1}(t)=\left\{\begin{array}{ccc}
A(R) \frac{R}{a} d R d \theta & \ldots & (0<t<\tau) \\
0 & \ldots & (\tau<t<T)
\end{array}=\sum_{1}^{\infty} A_{m} \cos \left(\text { mnat }-\varepsilon_{m}\right)+A_{0} ;\right. \\
& F_{2}(t)=\left\{\begin{array}{ccc}
B(R) \frac{R}{a} d R d \theta & \ldots & (0<t<\tau) \\
0 & \ldots & (\tau<t<T)
\end{array}=\sum_{1}^{\infty} B_{m} \cos \left(\text { mnat }-\mu_{m}\right)+B_{0}\right.
\end{aligned}
$$


Здесь $\theta$ - угол, $d \theta$ - элементарный угол в плоскости вращения, $\varepsilon_{\mathrm{m}}, \mu_{\mathrm{m}}-$ фазы, $A_{m}, \mathrm{Bm}-$ амплитуды гармоник, $\mathrm{m}$ - номер гармоники.

При этом

$$
\begin{aligned}
& A_{m}=\frac{2}{m \pi} A(R) \cdot \frac{R}{a} \sin \left(m \pi \frac{\tau}{T}\right) d R d \theta, \\
& B_{m}=\frac{2}{m \pi} B(R) \cdot \frac{R}{a} \sin \left(m \pi \frac{\tau}{T}\right) d R d \theta,
\end{aligned}
$$

Нас интересуют первые гармоники, имеющие частоту инфразвука. Для первых гармоник имеем

$$
A_{m}=\frac{n}{\pi} A(R) d R d \theta, \quad B_{m}=\frac{n}{\pi} B(R) d R d \theta .
$$

Потенциал скоростей, обусловленный сосредоточенной силой с компонентами X, Y, Z, определяется согласно [13]. С учетом того, что точка наблюдения лежит в плоскости $\mathrm{X}, \mathrm{Y}$ на расстоянии $\mathrm{r}$

$$
\phi=\frac{-i}{4 \pi \rho k c} X\left(\frac{1}{2 r}+\frac{i k}{r}\right) \cdot \frac{e^{-i k r}}{r} x \mid
$$

где $\rho$ - плотность среды, $k$ - волновое число, $c$ скорость звука, $x$ - координата.

Выражение для звукового давления в дальнем акустическом поле по [13] имеет вид

$$
p=\frac{m \omega_{1}}{2 \pi c r}\left[-P \cos \vartheta+\frac{n c}{\omega_{1} R_{2}^{2}} M\right] J_{m n}(k R \sin \vartheta)
$$

здесь $\vartheta$ - угол характеристики направленности, $\mathrm{x}$ / $\mathrm{r}=\cos \vartheta-$ направление косинуса радиусавектора, $\omega \mathrm{m}$ - круговая частота каждой из гармоник, r велико в сравнении с длиной волны и диаметром лопасти, где $\omega 1$ - круговая частота основного тона. $J_{m n}(k R \sin \vartheta)$ - Бесселева функция 1-го рода порядка $n$.

В данной работе получены и построены кривые характеристик направленности первых инфразвуковых гармоник шума, излучаемого ветроколесом (рис. 1). Для проведения расчетов составлены алгоритм и программа на языке MAPLE. B расчет заложены следующие исходные данные: число оборотов ветроколеса 46,7 об/мин.; скорость звука в воздушной среде $340 \mathrm{~m} / \mathrm{c}$; сила аэродинамического сопротивления $\mathrm{P}$ - $50000 \mathrm{H}$; величина движущего момента 7000 $\mathrm{H} \cdot$; число лопастей - 3 ; длина каждой лопасти 10 м; Расстояние вдоль лопасти до точки приложения аэродинамической силы равно 7,5 м;

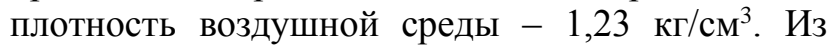

данных расчетов видно, что уровень звукового давления на расстоянии 300 м от ветроагрегата ВЭУ - 250С он составляет менее 80 дБ. Эта цифра удовлетворяет санитарным нормам.

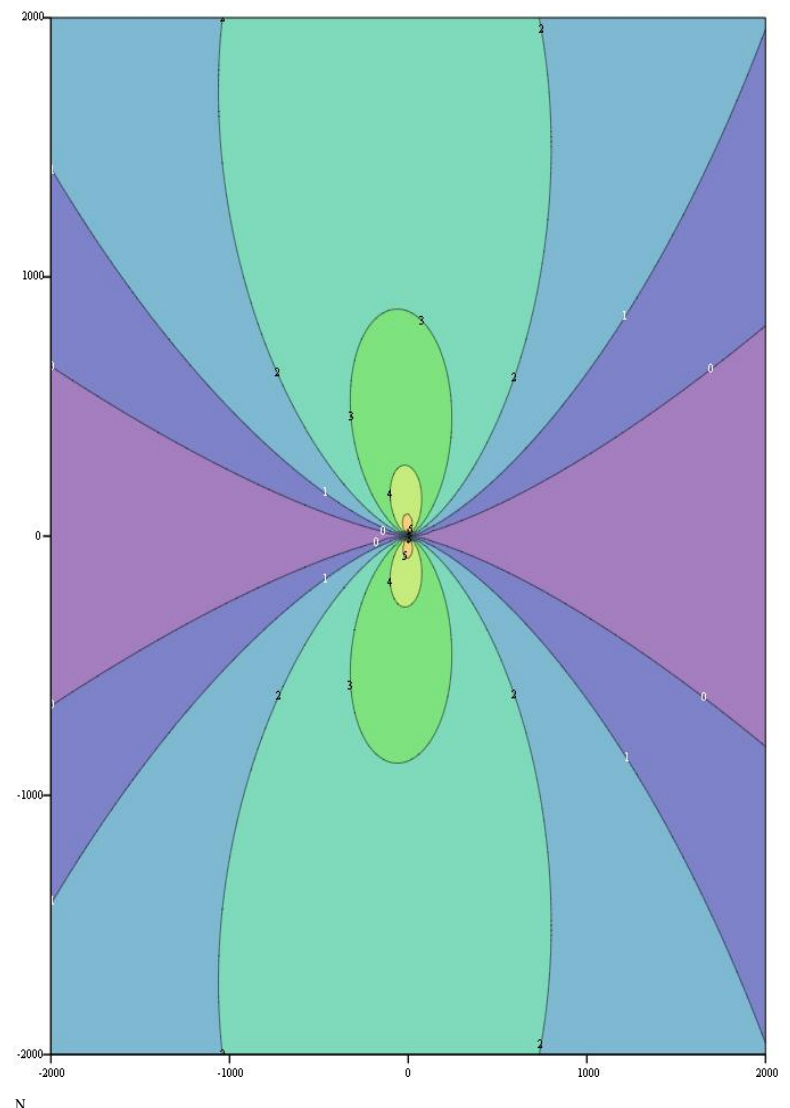

Рис. 1. Направленные характеристики инфразвуковых гармоник акустического поля ветрового колеса.

Fig. 1. Infrasonic harmonics' directional characteristics of the wind wheel acoustic field.

Излучаемая акустическая мощность согласно [13] определяется из выражения

$$
W=-\int_{0}^{\pi} \frac{p^{2}}{2 \rho c} 2 \pi r^{2} \sin \vartheta d \vartheta
$$

Из расчета по (2) следует вывод о том, что на акустическое излучение тратится $0,01 \%$ от общей мощности ВЭУ.

Выводы. Результатом проведенных исследований является формирование мероприятий по снижению уровня шумов инфразвукового диапазона. При проектировании инновационных систем энергообеспечения необходимо использовать компоненты, определяющие не только уровень шума, но и КПД используемых агрегатов. В условиях эксплуатации уменьшение УЗД в 
источнике шума достигается заменой шумного, устаревшего оборудования, правильным расчетом режима его работы:

- правильная ориентация источника шума, при необходимости изменение направленности. ВИЭ следует устанавливать так, чтобы излучение шума было направлено в сторону, противоположную жилым застройкам и общественным зданиям;

- размещение ВИЭ на необходимо удаленном расстоянии от жилой застройки;

- снижение скорости ротора в ночное время.

Так, например, для тепловых насосов выгодно использовать малошумные элементы, размещать компрессор снаружи здания или заключать его в звуконепроницаемую камеру. Размещать ВЭУ необходимо на удаленном расстоянии от жилой застройки.

Предложенная методика

позволяет эффективно провести расчет УЗД первых инфразвуковых гармоник (2,4 Гц; 4,8 Гц; 9,16 Гц; 18,32 Гц) и определить их характеристики направленности.

1. ДСН 3.3.6.037-99. Санітарні норми виробничого шуму, ультразвуку та інфразвуку. Головне санітарно епідеміологічне управління. К. Міністерство охорони здоров'я України. 1999. 79 с.

2. Сокол Г.И. Особенности акустических процессов в инфразвуковом диапазоне частот. Науч. Монография. Д. Промінь. 2000. 136 с.

3. ISO 3743-1:2010. Акустика. Определение уровней звуковой мощности и уровней звуковой энергии источников шума с использованием звукового давления. Технические методы для небольших подвижных источников в реверберационных полях.

4. Ребров Л.В. Отчет о результатах информационных исследований по теме: Экологическое обследование АВЭ250 С. Науч.-техн. отчет. Х.СВНЦ Акад. наук Украины. 1993. $96 \mathrm{c}$.

5. Хайнрих Г., Найорк Х., Нестлер В. Теплонасосные установки для отопления и горячего водоснабжения. М Стройиздат. $1985.351 \mathrm{c}$.

6. Техническое описание и инструкция по эксплуатации ветроэлектрической установки ВЭУ - 500 № 90.9990.0000.0000.01.0. Д. ГКБ «Южное». 1997. $65 \mathrm{c}$.

7. Сокол Г.И. Инфразвук - экологически вредный фактор в ветроэнергетике. Сб. трудов. Междунар. акуст. симп. "Консонанс - 2005". Киев. 27 - 29 сентября. 2005. К. 2005. C. 283-290.

8. Приходько А.А., Редчии Д.А. Компьютерное моделирование аэродинамики подвижных роторов ветроагрегатов Дарье и Савониуса. Аэрогидродинамика: проблемы и перспективы. 2006. Т. 2. С. 120-142.

9. Абрамовский E.P. Методика последовательных приближений в расчетах аэродинамических и энергетических параметров ветродвигателей. Вісн. Дніпроп. ун-ту. сер. Механіка. 2000. Вип. 3. Т. 1. С. 3-11.

10. Harvey H. Hubbard, Kevin P. Shepherd. Wind Turbine Acoustics. NASA Technical Paper 3057 DOE/NASA/20320-77. December. 1990. Pp. 1 - 46.
11. Суржик T.B. Деякі принципи підвищення ефективності використання теплонасосних установок. Відновлювана енергетика. 2012. №4(31). С. 86-90.
12. Гутин
Л.Я.
Избранные
труды.
Книга. Судостроение. Л. 1977. 730 с

13. Сокол Г.И., С.Ю. Кириченко. Инфразвуковые поля в ветроэнергетике в ракурсе экологической обстановки. Научно-техническая конференция «Водохозяйственное строительство, теплотехника и геология». Вестник Брестского гос. Университета. 2015. № 62(92). С. 112-114.

\section{REFERENCES}

1. DSN 3.3.6.037-99. Sanitarni normy vyrobnychoho shumu, ultrazvuku ta infrazvuku. [Sanitary standards of industrial noise, ultrasound and infrasound]. Main sanitary and epidemiological management. K. Ministry of Health of Ukraine. 1999. 79 p. [in Ukrainian].

2. Sokol G.I. Osobennosti akusticheskih processov v infrazvukovom diapazone chastot. [Features of acoustic processes in the infrasonic frequency range]. Scientific Monograph. D. Promin. 2000. 136 p. [in Russian].

3. ISO 3743-1:2010. Akustika. Opredelenie urovnej zvukovoj moshhnosti i urovnej zvukovoj jenergii istochnikov shuma $\mathrm{s}$ ispolzovaniem zvukovogo davlenija. Tehnicheskie metody dlja nebol'shih podvizhnyh istochnikov v reverberacionnyh poljah. [Acoustics. Determination of sound power levels and sound energy levels of noise sources using sound pressure. Technical methods for small moving sources in reverb fields]. [in Russian].

4. Rebrov L.V. Otchet o rezultatah informacionnyh issledovanij po teme: Jekologicheskoe obsledovanie AVE-250 S. [Report on the results of information research on the topic: Environmental survey AVE-250 S]. Nauch.-tehn. otchet. H. SVNC Akad. nauk Ukrainy. 1993. 96 p. [in Russian].

5. Hajnrih G., Najork H., Nestler $V$. Teplonasosnye ustanovki dlja otoplenija i gorjachego vodosnabzhenija. [Heat pump systems for heating and hot water]. M. Strojizdat. 1985. 351 p. [in Russian].

6. Tehnicheskoe opisanie i instrukcija po jekspluatacii vetrojelektricheskoj ustanovki AVE - 500 № 90.9990.0000.0000.01.0.TO. [Technical description and instruction manual for wind turbine wind turbine - 500 No. 90.9990.0000.0000.01.0]. D. GKB «Juzhnoe». 1997. 65 p. [in Russian].

7. Sokol G.I. Infrazvuk - jekologicheski vrednyj faktor v vetrojenergetike. [Infrasound is an environmentally harmful factor in wind energy]. Sb.trudov. Mezhdunar. akust. simp. “Konsonans - 2005". Kiev. 27 - 29 September. 2005. K. 2005. Pp. 283-290. [in Russian].

8. Prihodko A.A., Redchic D.A. Kompjuternoe modelirovanie ajerodinamiki podvizhnyh rotorov vetroagregatov Dare i Savoniusa. Ajerogidrodinamika: problemy i perspektivy. [Computer simulation of the aerodynamics of mobile rotors of Darier and Savonius wind turbines. Aerohydrodynamics: problems and prospects]. 2006. Vol. 2. Pp. 120-142. [in Russian].

9. Abramovskij E.R. Metodika posledovatelnyh priblizhenij $\mathrm{v}$ raschetah ajerodinamicheskih i jenergeticheskih parametrov vetrodvigatelej. [The method of successive approximations in the calculations of the aerodynamic and energy parameters of wind turbines]. Visn. Dniepropetrovsk. Univ. August. Mechanics. 2000. ed. 3. vol. 1. Pp. 3-11. [in Russian].

10. Harvey H. Hubbard, Kevin P. Shepherd. Wind Turbine Acoustics. NASA Technical Paper 3057 DOE/NASA/20320-77. December. 1990. Pp.1-46. [in English]. 
11. Surzhyk T.V. Deiaki pryntsypy pidvyshchennia efektyvnosti vykorystannia teplonasosnykh ustanovok. [Some principles for improving the efficiency of heat pump installations]. Vidnovluvana energetska. 2012. No.4 (31). Pp. 8690. [in Ukrainian].

12. Gutin L.Ja. Izbrannye trudy. [Selected Works]. Book. Sudostroenie. L. 1977. 730 p. [in Russian].

13. Sokol G.I., Kirichenko S.Ju. Infrazvukovye polja v vetrojenergetike $\mathrm{v}$ rakurse jekologicheskoj obstanovki. [Infrasound fields in wind energy from the perspective of the environmental situation]. Scientific and technical conference "Water management, heat engineering and geology". Bulletin of the Brest state. University. 2015. No. 62(92). Pp. 112-114. [in Russian].

\section{СИСТЕМИ ЕНЕРГОЗАБЕЗПЕЧЕННЯ 3 АЛЬТЕРНАТИВНИМИ ДЖЕРЕЛАМИ ЕНЕРГІЇ: БЕЗПЕКА ФУНКЦОНУВАННЯ АКУСТИЧНИХ ДЖЕРЕЛ У РОБОЧОМУ КЛІМАТИЧНОМУ СЕРЕДОВИЩІ}

Г.І. Сокіл, док. техн. наук, проф., Л.В. Накашидзе, докт. техн. наук, с.н.с. директор НДІ енергетики, С.Ю. Кириченко

Дніпропетровський національний університет імені Олеся Гончара

49050, пр-т Гагаріна, 72, Дніпропетровськ, Україна

Одним із наслідків позитивного процесу науки $і$ техніки супутні явища, в тому числі й негативні. При розробиі установок, щзо перетворюють енергію альтернативних джерел, ще на етапі проектування необхідно передбачати зниження рівнів інтенсивності иумів. Ці заходи необхідні для забезпечення захисту навколишнього середовища від иумового забруднення. Для розробки заходів, спрямованих на зниження звукового тиску (УЗД) в шумах до рівня, передбаченого нормативними документами [1], необхідно провести аналіз шумів від обладнання, яке забезпечує перетворення енергї̈ альтернативних джерел.

Для безпечного функиіонування таких установок необхідно:
- визначитися з джерелами акустичного випромінювання; - розробити теоретичні основи прочесу генерування шуму; - здійснити розробку розрахункових моделей характеристик акустичних полів.

У такому ракурсі, не викликає сумнівів актуальність проблеми зниження шумів від конструктивних елементів систем енергозабезпечення, у яких перетворюється енергія сонячного випромінювання, енергія вітрового потенціалу, тепло навколишнього середовища $i$ m.n. При иьому необхідно виключити шкідливий вплив шумів на людей на прилеглих територіях $і$ в житлових будівлях, а також живих мешканиів природи.

Результатом проведених досліджень є формування заходів щодо зниження рівня шумів інфразвукового діапазону. При проектуванні інноваційних систем енергозабезпечення необхідно використовувати компоненти, що визначають не тільки рівень шуму, але і ККД використовуваних агрегатів. Так, наприклад, для теплових насосів вигідно використовувати малошумні елементи, розмімувати компресор зовні будівлі або укладати його 6 звуконепроникну камеру. Розміщення ВЕУ на віддаленій відстані від житлової забудови.

Безперервний шум теплових насосів можна знижувати шляхом застосування ротаиійного компресора замість поршневого, відмовою від застосування клапанів, як у деяких ротаційних компресорах. Поршневі компресори слід добре балансувати для зниження вібрацій $i$ монтувати на віброгасильній підставі. Вибір холодоагенту може впливати на рівень шуму, Найкращим є більш щільна пара, але якщо з нею пов'язано підвищення тиску, то може бути $i$ зворотний ефект. $У$ вітроагрегатах пропонується зниження швидкості ротора в нічний час.

Запропоновано методику, яка дозволяє ефективно провести розрахунок УЗД перших інфразвукових гармонік (2,4 Гц; 4,8 Гц; 9,16 Гu; 18, 32 Ги) $і$ визначити їх характеристики спрямованості. Бібл. 13, рис. 1.

Ключові слова: иуми, зниження, теплові насоси, вітроагрегати, методика розрахунку, інфразвукові гармоніки. 